\title{
EVALUATION OF AN INTERVIEW TRAINING COURSE FOR GENERAL PRACTITIONERS
}

\author{
J. M. Bensing and E. M. Sluus \\ Nederlands Instituut voor Onderzoek van de Eerstelijnsge Zondheidszorg. Postbus 1568, 3500 BN. \\ Utrecht, The Netherlands
}

\begin{abstract}
This article describes the evaluation of an experimental training in doctor-patient communication for general practitioners. The training was based on Rogerian theory and accommodated to the specific situation of the general practitioner. The main concept of this theory is the notion of 'unconditional positive regard'. It was expected that doctors would change their communication behaviour and that as a result patients would talk more about their psychosocial problems. The training was restricted to the diagnostic process, no therapeutic interventions were taught.

The effects of this training have been measured by comparing video-tapes of live doctor-patient consultations. before and 3 months after the training. The most important result of this evaluation study turned out to be the change of the doctor's behaviour in the expected direction, but surprisingly the outcome of the consultation did not change at all: the doctors were empathically listening, but the pattents did not talk morc about their problems.

Creating room for patients is not sufficient to induce them to discuss their personal problems with their doctors. Perhaps they do not feel like discussing their personal problems with them at all.
\end{abstract}

\section{INTRODUCTION}

General practice has increasingly become an interdisciplinary science, a melting pot of the medical and social sciences. From the moment that professional training courses started in The Netherlands (in 1973) social scientists have been involved in education and research in this area. There can be little doubt that this type of collaboration between medical and social sciences is connected with the growing interest in the psychosocial problems of general practice. In order to solve these problems, attempts are being made to assess whether certain elements taken from psychological theories of care might be of use to the general practitioner. The traditional medical approach to the detection and treatment of psychosocial problems has proved less than satisfactory. Consequently, the need has arisen to borrow freely from promising related disciplines. In this context, courses in interview training for general practitioners have been in existence for several years in The Netherlands. These courses are partly based on the theories of Rogers [1]. One of the central themes of these theories is the notion of "unconditional positive regard'. This implies that those in the caring professions are, above all, expected to assume a passive, attentive and empathic attitude in which listening plays the most important part. This desired type of attitude is, of course, rather different from the active type of behaviour that normally characterizes family doctors. The Netherlands Institute of Primary Health Care has examined as to how far practising general practitioners are able to acquire the relevant skills from training courses

*The Netherlands Institute of Primary Health Care (NIVEL) proceeds from the Netherlands Institute of General Practitioners (NHI). The article is available in Dutch language in: Nederlands Tijdschrift voor de Psychologie en haar grensgebieden. and what effects this has on their care. This article constitutes a summary report of this research.

\section{RESEARCH FRAMEWORK}

The effects of an interview training-course for general practitioners (GPs) have been examined with the aid of video-recordings of consultations. Two months before the first training sessions pre-test measurements were taken with the participating GPs and post-test measurements were taken 3 months after the last session. The camera was fixed with no cameraman present in the consultation room. Only complete consultations were recorded. The video material was scored on specially designed observations forms. Each consultation was scored independently by two observers. For data concerning inter-observer reliability see Refs [3-5].

The training course was given by psychologists. The aims of the course were formulated as follows:

(1) The training concerns interviewing skills (and is therefore different from personality training).

(2) The training is not aimed at medical therapy strategies (i.e. it is non-therapeutic), but rather concentrates on the creation of optimal condition for the patient to express possible psychosocial problems (i.e. it is diagnostic).

(3) The skills acquired during training are considered to be generalizable to the general practice situation.

\section{DEFINITION OF THE RESEARCH PROBLEM}

The general hypothesis which lays at the basis of this research is as follows: when a practitioner has followed an interview training course, he will be more capable of creating the kind of conditions in which patients of any kind are able and prepared to bring forward, and possibly discuss the psychosocial aspects of their complaints and problems. 
Three research questions may be deduced from this general hypothesis:

(1) Has the GPs' interview behaviour substantially changed after the training in comparison with their behaviour before?

(2) If so, do they really give their patients more room during consultations to bring forward psychosocial aspects or problems?

(3) Are psychosocial aspects and problems during consultations in effect discussed more frequently after the training than before?

The following section first contains a discussion of the manner in which the three questions just formulated have been investigated and secondly a presentation of the results.

\section{OBSERVATION SCHEME}

In attempting to answer the first question concerning the interviewing behaviour of GPs the extensive system of interview categories proposed by Byrne and Long [2] was used. This system allows for an exhaustive description of the GPs' interviewing behaviour, since every utterance can be classified under one of the 50 possible categories. In this way an interviewing profile emerges for each practitioner who has registered exactly how often he "asks direct questions" how often he 'reflects', how he 'gives information' etc. The system of categories is usable for our purposes, because it contains (inter alia) all the behavioural items explicitly aimed for during the training sessions. NHI research in other areas has confirmed the reliability of this system, yielding inter-observer correlation coefficients from 0.40 to 0.87 [3].

The second research problem concerns the amount of room given to the patient during the consultation. This concept has been defined and made operational in different ways according to the literature. In general it refers to the chances which paticnts get during interviews to bring forward their real worries. In the article "Room for the patient" [4] various possible ways of operationalizing this concept are described and interconnected. A number of these variables have also been measured in this research. namely:

the duration of the consultation (this being an objective measure for the time devoted by the GP to his patient),

the speaking-time ratio between GP and patient.

the frequency with which the GP looks at the patient during the interview (measured literally as looking-time),

the attention, interest and calmness of the GP during the consultation (scored by means of a five-point scale).

The third question is related to the degree to which psychosocial aspects are being raised during the consultation. Here too variables were used which had proved useful in earlier research at the NHI [5]. In this research two aspects are of high importance: the frequency with which the physician perceives psychosocial aspects in the complaints of his patient, called psychosocial diagnosis; and the frequency with which the physician and his patient actually talk about these psychosocial aspects, expressed in the number of psychosocial consultation fragments.

\section{RESULTS}

\section{Background data}

In Table 1(a) and 1(b) the pre-training and posttraining measurements concerning the number of consultations per GP are presented. The figures for the number of consultations are self-explanatory. With regard to the age distribution of patients it should be noted that the post-test figures show many more older patients for GP 6; this will have to be taken into account in the analyses. The post-tcst

Table I.(a) Number of consultations and classification of sex in pre- and post-test

\begin{tabular}{|c|c|c|c|c|c|c|c|c|c|c|c|c|c|c|c|}
\hline & & \multicolumn{2}{|c|}{ GPI } & \multicolumn{2}{|c|}{ GP2 } & \multicolumn{2}{|c|}{ GP3 } & \multicolumn{2}{|c|}{ GP4 } & \multicolumn{2}{|c|}{ GP5 } & \multicolumn{2}{|c|}{ GP6 } & \multicolumn{2}{|c|}{ Total } \\
\hline & & pre & post & pre & post & pre & post & pre & post & pre & post & pre & post & pre & post \\
\hline \multicolumn{2}{|c|}{ Number of consultations } & 18 & 15 & 12 & 13 & 14 & 15 & 20 & 15 & 17 & 13 & 25 & 10 & 106 & 81 \\
\hline \multirow{2}{*}{ Sex } & Mole & 1 & 4 & 1 & 2 & 4 & 7 & 5 & 6 & 10 & 3 & a & 4 & 29 & 26 \\
\hline & Female & 17 & 11 & $\uparrow 1$ & 11 & 10 & 8 & 15 & 9 & 7 & 10 & 17 & 6 & 77 & 55 \\
\hline
\end{tabular}

Table 1.(b) Classification of age of patients in pre- and post-test

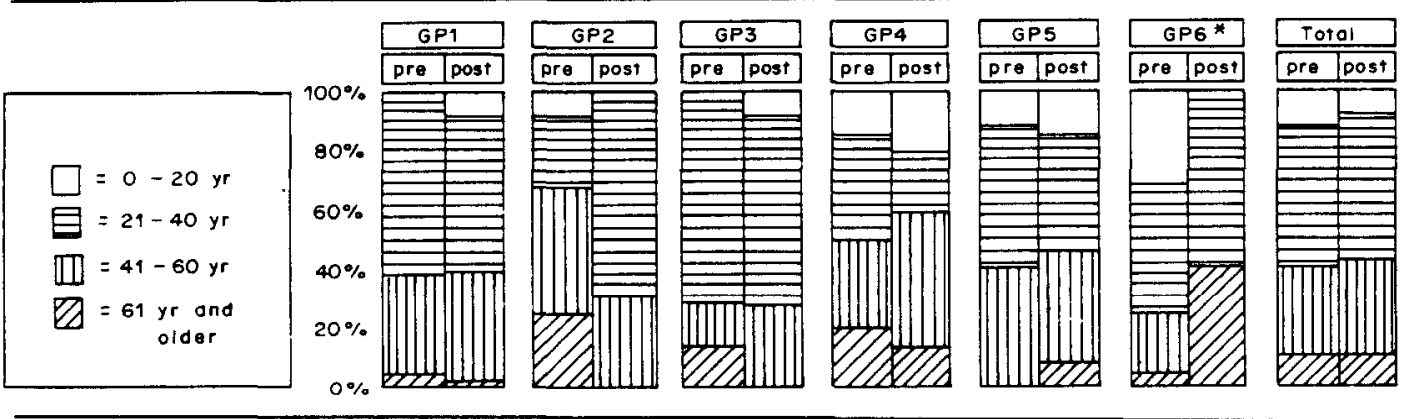

*Significant difference pre-test and post-test $P<0.05$. 
figures show relatively fewer men and more women for GP 5. Note also that the total random test contains a higher percentage of women $(68 \%)$ compared to the percentages $(57 \%)[6,7]$ found in other studies. We have no explanation for this phenomenon.

Question I-How far have the GPs changed their behaviour after the training?

In Table 2 the data concerning the interviewing behaviour of the GP are shown. In the evaluation of the results all the 50 interview categories used by Byrne and Long have been applied, but for the sake of clearness we only present here those categories which occur in at least $20 \%$ of the consultations. Table 2 shows how often each GP uses a particular category per 10 consultations. By using a two-tailed $t$-test we have checked both for one physician and for all physicians together which categories are being used significantly more or less in the postmeasurement in comparison with the premeasurement. The fact that the same differences are significant in one category and not in other categories is caused by the big differences in the standard deviations. Moreover the numbers in Table 2 have been rounded, by which means the differences sometimes seem smaller than they really are.

For those who are not deterred by this, Table 2 contains some potentially interesting data. Starting with the last column, in which the average frequency of interview categories for the total number of GPs is shown, we can deduce from the post-test figures 11 categories which have been used significantly more These are mainly the categories which refer to the empathic behaviour of the GP, who is explictly tackled in training. It also turns out that the GPs are more informative and provide more explanations to the patients after the training. There is only one

Table 2. Pre- and post-training interview profiles per GP and per group

\begin{tabular}{|c|c|c|c|c|c|c|c|c|c|c|c|c|c|c|}
\hline & \multicolumn{2}{|c|}{ GP 1} & \multicolumn{2}{|c|}{ GP 2} & \multicolumn{2}{|c|}{ GP 3} & \multicolumn{2}{|c|}{ GP 4} & \multicolumn{2}{|c|}{ GP 5} & \multicolumn{2}{|c|}{ GP 6} & \multicolumn{2}{|c|}{ Total } \\
\hline & Pre & Post & Pre & Post & Pre & Post & Pre & Post & Pre & Post & Pre & Post & Pre & Post \\
\hline 1 Closed question & 3 & 3 & 4 & 5 & 9 & 3 & 1 & 13 & 5 & 11 & 2 & 1 & 4 & 6 \\
\hline 2 Direct question & 24 & 33 & 31 & 29 & (68) & 38 & 37 & 31 & 49 & 60 & 46 & 44 & 42 & 38 \\
\hline \multicolumn{15}{|l|}{4 Placing events in time/sequence } \\
\hline place & & & & & 17 & 9 & 8 & 2 & 14 & 19 & 9 & 9 & 9 & 10 \\
\hline 5 Relating to previous experience & 4 & 5 & 4 & 8 & 6 & 5 & 5 & 3 & & 7 & 2 & 4 & 4 & 5 \\
\hline 7 Open question & 6 & 4 & & (12) & 4 & 7 & 9 & 10 & & (10) & 7 & 5 & 6 & 8 \\
\hline 8 Exploring & 12 & 15 & & 36 & 27 & 26 & 15 & 16 & 17 & 26 & 14 & 18 & & \\
\hline 9 Seeking patient ideas & 0 & 2 & 5 & 6 & 3 & 6 & 2 & 9 & 4 & 2 & 2 & 6 & & 5 \\
\hline 10 Encouraging & 19 & 23 & 23 & (60) & 16 & 14 & 20 & 48 & 15 & 7 & & & & \\
\hline 12 Reflecting & 2 & 2 & 2 & 10 & 8 & 9 & 2 & 4 & 3 & 3 & & & & \\
\hline 13 Offering observation & & & 1 & 2 & 9 & 6 & 2 & 4 & 2 & 2 & 3 & & & \\
\hline 14 Offering of feelings & & (18) & 5 & 19 & 10 & 12 & 5 & 8 & 8 & 10 & & & & \\
\hline 16 Indicating understanding & 55 & 88 & 58 & (208) & 76 & 70 & 69 & 117 & 67 & 83 & & & & \\
\hline \multicolumn{15}{|l|}{17 Repeating patient words for } \\
\hline affirmation & 3 & 9 & 5 & 11 & 14 & 5 & 14 & 13 & 11 & 9 & 7 & 12 & 9 & 10 \\
\hline 21 Apologizing & 1 & 5 & 2 & 2 & 5 & 5 & 3 & 8 & 4 & 8 & 1 & 10 & & \\
\hline 24 Directing & 53 & 65 & 63 & 49 & (92) & (61) & 52 & 64 & 71 & 63 & 63 & 64 & 64 & 61 \\
\hline \multicolumn{15}{|l|}{25 Giving convincing information or } \\
\hline opinion & 15 & 16 & 13 & 17 & 13 & 22 & 23 & 35 & (B) & (19) & 12 & 33 & & \\
\hline 26 Suggesting & 12 & 12 & 18 & 21 & 33 & 28 & 14 & 15 & 18 & 14 & & & 17 & 20 \\
\hline 27 Reassuring & 8 & 9 & 14 & 8 & 12 & 9 & 2 & 6 & 6 & 11 & & & 7 & 9 \\
\hline 28 Advising & 8 & 11 & 10 & 10 & 11 & 13 & 11 & 11 & 11 & 12 & 8 & 24 & 10 & 13 \\
\hline 29 Giving neutral information or opinion & 33 & 42 & 40 & 49 & 53 & 42 & 36 & 38 & 34 & 35 & & & & \\
\hline 30 Clarifying & (14) & (25) & 16 & 16 & 20 & 21 & 16 & 21 & 18 & 12 & & & & \\
\hline 31 Answering patient question & 29 & $2 \overline{4}$ & 43 & 32 & 32 & 33 & 32 & 41 & 21 & 20 & & & 29 & 36 \\
\hline 32 Accepting patient ideas & 4 & 8 & 17 & 15 & 8 & 13 & 7 & 11 & 9 & 7 & & & & \\
\hline 33 Using patient ideas & 2 & 3 & 2 & 2 & 3 & 3 & 2 & 0 & 3 & 3 & 1 & 2 & 2 & 2 \\
\hline \multicolumn{15}{|l|}{34 Suggesting or accepting } \\
\hline collaboration & 1 & 2 & 9 & 5 & 9 & 6 & 5 & 2 & 3 & 2 & & & 4 & 4 \\
\hline 36 Summarizing to close of & 2 & 2 & 4 & 3 & 4 & 1 & 3 & 5 & 4 & 2 & & & 3 & 3 \\
\hline 37 Indirect terminating & 8 & 9 & $(7)$ & (10) & 8 & 8 & 7 & 5 & 7 & 9 & & & & \\
\hline 39 Confused noise & 1 & 1 & 5 & 3 & 6 & 6 & (11) & & & & $\overline{0}$ & 5 & 4 & 3 \\
\hline 40 Not-interested 'yes. yes' utterances & 6 & 3 & 7 & 2 & 4 & 4 & 4 & 11 & 1 & 4 & 2 & 5 & 4 & 5 \\
\hline 41 Interrupting jumbled speech & & & 5 & 2 & 18 & 5 & 13 & 11 & 5 & 8 & 4 & 2 & & 6 \\
\hline 42 Ignoring patient not listening & 11 & 12 & 14 & 10 & 11 & 9 & 13 & 18 & 6 & 12 & 13 & 14 & 11 & 12 \\
\hline 46 Expressing satisfaction with & & & & & & & & & & & & & & \\
\hline & & & 2 & 5 & 5 & 4 & 4 & 1 & 1 & 2 & 1 & 6 & 2 & 4 \\
\hline
\end{tabular}


Table 3. Factor analysis: pre- and post-test factor loads and factor scores

\begin{tabular}{|c|c|c|c|c|c|c|c|c|}
\hline \multicolumn{3}{|c|}{ Factor 1: Informative behaviour } & \multicolumn{3}{|c|}{ Factor 2: Empathic behaviour } & \multicolumn{3}{|c|}{ Factor 3: Directive behaviour } \\
\hline \multicolumn{2}{|c|}{$\begin{array}{l}\text { Giving convincing } \\
\text { information }\end{array}$} & 0.66 & \multicolumn{2}{|l|}{ Exploring } & 0.62 & \multicolumn{2}{|c|}{ Closed question } & 0.39 \\
\hline \multirow{2}{*}{\multicolumn{2}{|c|}{$\begin{array}{l}\text { Suggesting } \\
\text { Reassuring }\end{array}$}} & 0.52 & \multicolumn{2}{|c|}{ Seeking patient ideas } & 0.57 & \multirow{2}{*}{\multicolumn{2}{|c|}{$\begin{array}{l}\text { Direct question } \\
\text { Placing events in time }\end{array}$}} & 0.76 \\
\hline & & 0.44 & \multicolumn{2}{|c|}{ Encouraging patient } & 0.67 & & & \\
\hline \multicolumn{2}{|c|}{ Giving neutral information } & 0.62 & \multicolumn{2}{|c|}{ Reflecting } & 0.68 & \multicolumn{2}{|c|}{ Tlacing creits hit inte } & 0.55 \\
\hline \multicolumn{2}{|c|}{ Clarifying } & 0.55 & Offering of fee & & 0.43 & \multicolumn{2}{|c|}{ Exploring } & 0.42 \\
\hline \multirow{2}{*}{\multicolumn{2}{|c|}{$\begin{array}{l}\text { Answering patient question } \\
\text { Accepting patient ideas } \\
\text { (var. } 62.5^{\circ} \text {. Eigenvalue } 5.75 \text { ) }\end{array}$}} & 0.77 & \multicolumn{2}{|c|}{ Indicating understanding } & 0.78 & \multicolumn{2}{|c|}{ Repeating for affirmation } & 0.63 \\
\hline & & 0.42 & \multicolumn{3}{|c|}{ (var. $21.1^{\circ}$, Eigenvalue 1.94 ) } & \multicolumn{3}{|c|}{$\begin{array}{l}\text { Directing } \\
\left(\text { var. } 16.4^{n}{ }_{0} \text { Eigenvalue } 1.51\right)\end{array}$} \\
\hline Factor scores & Pre & Post & Factor scores & Pre & Post & Factor scores & Pre & Post \\
\hline GP I & -0.07 & -0.02 & GP 1 & -0.34 & -0.07 & GP 1 & -0.50 & -0.10 \\
\hline GP 2 & 0.31 & -0.13 & GP 2 & $-0.23^{*}$ & $1.10^{*}$ & GP 2 & -0.29 & -0.18 \\
\hline GP 3 & 0.20 & 0.12 & GP 3 & -0.01 & 0.12 & GP 3 & $-0.82^{*}$ & $-0.05^{*}$ \\
\hline GP 4 & 0.05 & 0.32 & GP 4 & -0.22 & 0.21 & GP 4 & -0.06 & -0.25 \\
\hline GP 5 & -0.31 & -0.23 & GP 5 & -0.13 & -0.11 & GP 5 & 0.23 & 0.45 \\
\hline GP 6 & $-0.30^{*}$ & $1.27^{*}$ & GP 6 & $-0.51^{*}$ & $0.06^{*}$ & GP 6 & 0.03 & 0.03 \\
\hline Total & -0.06 & 0.18 & Total & $-0.27^{*}$ & $0.21^{*}$ & Total & 0.02 & -0.03 \\
\hline
\end{tabular}

*Significant difference pre- and post test $P \leqslant 0.05$.

category which occurs significantly less frequent after training: GPs interrupt their patients less often (category No. 41).

In spite of these figures it may not be concluded from these data that interview training has had the same positive effect on all GPs: there are considerable differences. GP 6 is the one who has changed most in every respect, although it should be noted that his patients are considerably much older post-test than pre-test. GP 2 and, to a less extent GP 1, also show some changes. The GPs 3, 4 and 5 hardly seem to have changed at all.

This plethora of data has been reduced by means of a factor analysis (see Table 3) in which only those categories are used which occur at least in $20 \%$ of the consultations. A forced three-factor solution with varimax rotation yielded three dimensions which are interpreted as follows.

The first factor reflects the amount of information and explanation which the GP gives to the patient, the second factor denotes the empathic behaviour of the GP and the third indicates the controlling and guiding role assumed by the GP in the consultation. Below the factor solutions in Table 3 the factor scores for each GP are shown as well. In the computation of these scores we have checked by means of a $t$-test whether or not the pre- and post-test figures differ significantly for thcse factor scores.

It appears from this analysis as well (see Table 3 ) that the training has had the biggest effect on the empathic behaviour of the GPS (factor 2). Each GP has a higher post-test factor-score (significant for the GPs 2 and 6), which makes factor 2 the only factor that shows a significant change for the whole group. In sum: it appears that training has had indeed some effect on the GPs' behaviour. The biggest changes are to be found in the so-called 'empathic' behaviour of the GPs, this being the type of behaviour which occupied a central position in the training. Particularly in the case of two GPs (Nos 2 and 6) these changes must be considered to be remarkable.

Question 2-Does the patient get more room in the consultation?

The variables referring to the room a patient gets in the consultation can be found in the Tables 4(a), (b) and (c). In Table 4(a) the average duration of a consultation can be found and also the percentage of this time during which the practitioner looks at his patient. In Table 4(b) we have calculated the proportion of conversation-time of the practitioner and his patient. Further, the observer's judgment concerning the practitioner's attention can be found in Table 4(c). With regard to the latter variables we distinguish between conversations about somatic matters, the so-called somatic consultation-fragments, and conversations about psychosocial subjects, called psychosocial consultation-fragments. By means of a two-tailed $t$-test we have checked again which variables show significantly different scores in the postmeasurement compared to the pre-measurement. It appears that interview training for GPs produces a considerable amount of room for the patient. All variables show a significant post-test difference, at least as far as the group average is concerned. The GPs shows more attention, interest and calmness in the consultation, they look at their patients more often and talk less themselves. As a result of this the patient starts to talk more and the average consultation lasts longer. However, this change does not hold for all GPs equally and therefore it will be interesting to consider the - sometimes considerableindividual differences between the GPs.

Starting with the consultation-time we perceive that this has increased for all GPs except for GP 3 . This is the one who shows less 'directive behaviour" in the post-measurements (factor 3) and who is consequently more attentive and calmer and looks more often at his patients. Evidently not every positive change in the GPs' behaviour is by definition more 'time-consuming'. Studying the post-test figures we perceive that the GPs 2 and 6 are the ones who look at their patients significantly more often. For all GPs the proportion of conversation-time between GP and patient has changed in the same direction: the post-test figures show that the patients speak more often and longer. It should be noted that this change has been effected in different ways: a few GPs are more attentive and more interested, some look at their patients more often or behave calmer during the consultation, and other practitioners actively encourage their patients to talk more, etc. 
Table 4.(a) Room-for-the-patient variables: consultation-time and looking-time

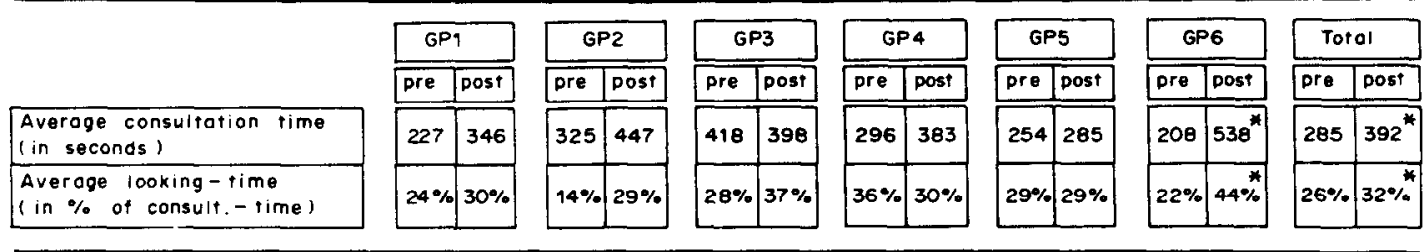

*Significant difference pre- and post-test $P \leqslant 0.05$.

Tuble 4.(b) Room-for-the-paticnt variables: speaking-time ratio GP/patient

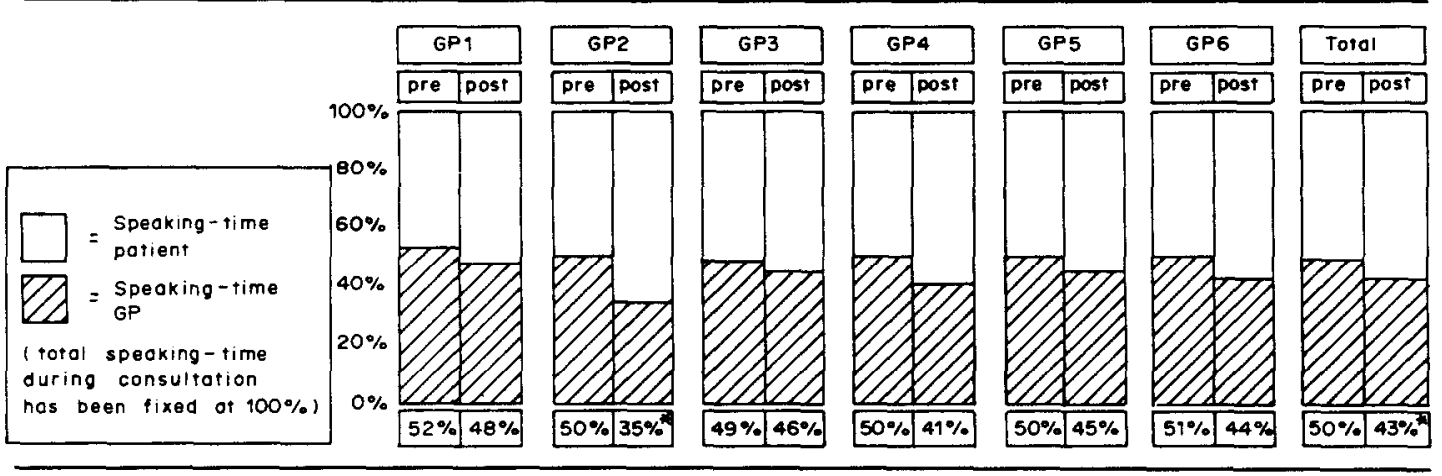

* Significant difference pre- and post-test $P \leqslant 0.05$.

Table 4.(c) Room-for-the-patient variables: scores for attention, interest and calmness

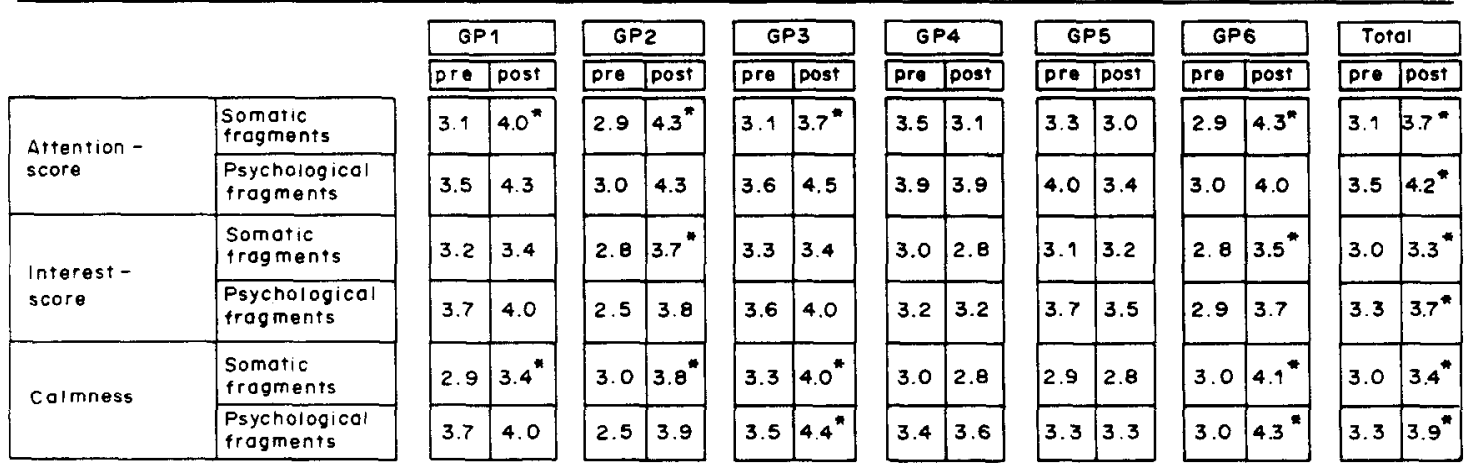

*Significant difference pre- and post-test $P \leqslant 0.05$.

Question 3-Are psychosocial problems discussed more often after the training?

Now that it is evident from the post-test figures that the patients receive more room after the training, it will be interesting to find out whether psychosocial problems are discussed more often after the training than before. The results are shown in Table 5 .

The number of psychosocial conversationfragments is herewith used as a measure. These fragments should be regarded in relation to the number of psychosocial diagnoses the practitioner makes. First of all it is striking that GPs diagnose a case more often psychosocial than they discuss these matters with their patients. In all cases there are less psychosocial conversation fragments (the striped side) than psychosocial diagnoses (the front screen). With regard to the pre- and post-measurement it is striking that the relative number of consultations in which the complaints of the patients are judged as psychosocial has not substantially changed for any of the practitioners (what we do find here are enormous differences between the practitioners).

In this connection it is disappointing to discover that the percentage of consultations in which doctor and patient discuss the psychosocial aspects of a complaint together has hardly increased in the posttest figures. The ratio has remained practically the same for all GPs with the exception of GP 2. Evidently the fact that the patient is given more room does not automatically imply that the patient really uses this room to discuss psychosocial matters (as we have seen earlier, the patient starts to talk more, but this only regards the pure medical aspect of his complaint). All in all we may conclude that the training appears to have had little effect on the measure in which the physician observes psychosocial 
Table 5. Percentage of consultations with a psychosocial diagnosis and with psychosocial interview fragments

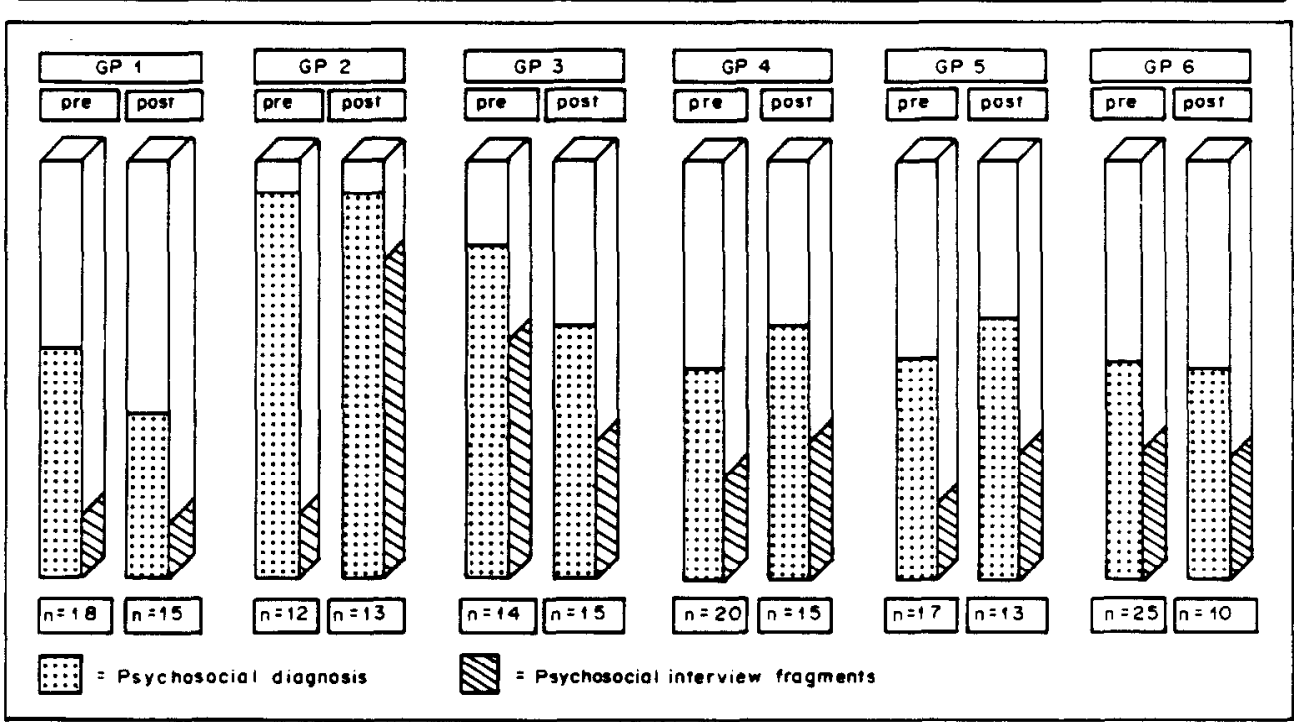

aspects and no more on the measure in which psychosocial problems are actually discussed. It seems that the patient does not just use the offered room for sluicing his problems.

\section{An illustration: $G P 6$}

The previous sections contain numerous figures which form the basis for many conclusions. Many readers may well question the validity of these figures. What do they stand for? Do they present a true picture of what is actually going on in surgery? Moreover, do the postulated changes reappear in the consultations? In order to answer these questions we have been looking for adequate illustrative material in the raw video-data. We chose GP 6 because he showed the most changes across the board. Earlier we saw that this GP had a larger number of older patients in the post-test than in the pre-test. In order to eliminate this factor we looked for comparable types of patients in the pre- and post-test figures.

We found two women, aged 30 and 35 , who both presented complaints concerning feelings of general malaise. First we shall present the core figures for both consultations. These are as follows:

Pre-test

$\begin{array}{ll}\text { Time of consultation } & =5 \mathrm{~min} 20 \mathrm{~s} \\ \text { Looking-time GP } & =11 \% \\ \text { Speaking-time GP } & =76 \% \\ \text { Speaking-time patient } & =24 \% \\ \text { Attention GP } & =\text { Score } 3 \\ \text { Interest GP } & =\text { Score } 2.5 \\ \text { Calmness GP } & =\text { Score } 3\end{array}$

Interview profile

Total number of utterances by GP in this consultation Number utterances factor 1 (i.e. 'informative behaviour') Number utterances factor 2 (i.e. empathic utterances) Number utterances factor 3 (i.e. directive behaviour) Other utterances

\section{Post-test}

Time of consultation $=13 \mathrm{~min} 35 \mathrm{~s}$

Looking-time GP $\quad=42 \%$

Speaking-time GP $\quad=44 \%$

Speaking-time patient $=56 \%$

Attention GP = Score 4

Interest GP = Score 4

Calmness GP = Score 4

Interview profile

Total number of utterances

by GP in this consultation

Number utterances factor 1

(i.e. 'informative behaviour')

Number utterances factor 2

(i.e. empathic utterances)

Number utterances factor 3

(i.e. directive behaviour)

Other utterances

$$
\begin{aligned}
& =79=100 \% \\
& =21=27 \% \\
& =37=46 \% \\
& =15=19 \% \\
& =6=8 \%
\end{aligned}
$$

According to these core figures the post-test behaviour of the GP in question differs markedly from his pre-test behaviour in that he leads less and is more empathic. The patient is given considerably more room. As regards the consultations proper, these were recorded as follows.

Pre-test consultation fragments of GP 6

The patient is a woman of 30 .

Pt. $=$ I feel absolutely terrible

GP. $=$ Still? (Docs not look up)

Pt. = Yes, and my head is still, you know, it's still there. And I am terrible tired, and I still feel as if I could fall apart any minute

GP. = We'd better check your blood pressure and have a look at your sinuses

Could you step inside there, please? (GP looks up and points to the examination room)

GP. $=$ Do you have a temperature?

$\mathrm{Pt}_{1}=$ No...

GP. = But do you have dizzy spells?

$\mathrm{Pt} .=$ Yes

GP. = Could you open your mouth and say 'ah' please...? Could you clear your nose, please...?... Lift your arms, would you? 
$\mathrm{Pt} .=$ Whenever I do anything I'm completely exhausted afterwards

GP. = But did you allow yourself to shake off your illness?

$P t .=I$ got up only yesterday

GP. $=$ Could you stand up for a moment, please? Do you have a cough?

$\mathrm{Pt}_{\mathrm{t}}=$ Not really, sometimes, but nothing serious

$\mathrm{GP} .=$ That looks quite allright really. Surely headache isn't as bad as it was, is it?

$\mathrm{Pt} .=$ Sorry?

GP. = Is your headache not a bit better?

$\mathrm{Pt} .=$ Yes, it's gone down

$\mathrm{GP} .=$ Because it looks quite clear up there

$\mathrm{Pt} .=$ Yes, it's gone down, but I still have it though. Of course I still have a nightjob and I'm still on sickness benefit

GP. $=$ I'll give you some dihydergot to relieve the dizziness and tiredness, and I will also give you some vitamin B complex. I would like you to go to my assistant to check for possible anaemia

$\mathrm{Pt} .=$ All right, doctor

GP. $\approx$ And eh, we'll just see for a week how it goes on, and stay off work for the time being

$\mathrm{Pt}$. = All right. Did you say I should stay off work?

$\mathrm{GP} .=$ That's right

$\mathrm{Pt} .=\mathrm{Oh}$, I see... but then I'll have to ... because I got one of those forms you know..

GP. = I would simply give in if I were you and have lots of sleep. Somebody who's been ill, it really affects your body and it needs time to recover from the illness. You shouldn't force it. But your blood pressure is a bit on the low side so that could be the cause as well. That's why I want to check whether you're anaemic. Don't hesitate to come back if you're not all right by next week

$\mathrm{Pt} .=$ All right, doctor Consultation ends.

Post-test consultation fragments of GP 6

The patient is a woman of 35 .

$\mathrm{Pt} .=$ Well doctor , this is not exactly what I expected

GP. $=$ (Looks up) Óh, how's that?

Pt. = Well I'm feeling absolutely terrible and it's getting worse

$\mathrm{GP} .=$ (nods)

$\mathrm{Pt}_{\mathrm{f}}=\mathrm{I}$ feel really ill, do you know that?

GP. $=$ Do you?

$\mathrm{Pt} .=$ The funny thing is I couldn't tell you where it hurts

$\mathrm{GP} .=\mathrm{H}^{\prime} \mathrm{m}$

$\mathrm{Pt} .=\mathrm{I}$ have a headache though

$\mathrm{GP} .=\mathrm{H} \cdot \mathrm{m}$

Pt. = In the afternoon, dear oh dear. every step is an effort.

$\mathrm{GP} .=\mathrm{H}^{\prime} \mathrm{m} . \mathrm{h}^{\prime} \mathrm{m}$

$P_{t}=$ And yesterday afternoon, 1 was doing the hoovering. I had been sitting for a while and then I got up to take the hoover and... whoops...there I went, I nearly keeled over

$\mathrm{GP} .=$ (nods)

$\mathrm{Pt} .=$ So when I really stoop down or get up quickly, everything sort of falls away

GP $=$ (nods)

$\mathrm{Pt} .=$ And I get it in the afternoon too. It feels as if I'm just about to faint all the time, not really fainting you know, but feeling like

$\mathrm{GP} .=$ (nods)

$\mathrm{P}_{\mathrm{t}}=\mathrm{I}^{\prime} \mathrm{m}$ really fed up with this. Sunday morning my eye was completely shut and all blue and yellow underneath

$\mathrm{GP} .=($ nods $)$

GP. = What about sleeping? Do you sleep alright?
Pt. = Oh, well, I wake up regularly, but I've no difficulty in falling asleep again. So that's no problem really. When I go to bed I just fall asleep after a while, so that's not bad

GP. = It doesn't sound as if you're completely happy about it though

$\mathrm{Pt} .=($ silence $) \ldots$ Well, I can't say I am of course. I mean I'm happy enough whenever I can go to bed...I suppose.

(and later)

Pt. = What about the dizziness? What could that be?

GP. = The blood pressure of yours is bound to fall occasionally when you get up. You simply can't keep it at the required level. For us that's an indication of over-tiredness. And of course, being on the go all the time, or having been, without stopping. We might have a look at your sinuses to see if they're infected perhaps and we could check for possible anaemia. It's a possibility, but we won't know until the middle of next week

$\mathrm{Pt} .=\mathrm{Oh}$, and I've been using nasepert... do I have to keep taking that?

GP. = Well, that doesn't seem to be doing a lot of good, does it? When you keep having trouble, you might as well stop taking that

(after some more appointments the consultation ends).

It is almost too good to be true: the GP's post-test behaviour shows a real difference from his pre-test behaviour (validity!). And, moreover, his post-test behaviour is a perfect reflection of what he has learned in training. However, in reality we see here what the figures in the last paragraph already suggested: the result of the consultation is exactly the same in both cases. The GP doesn't choose another form of treatment, since in both cases X-rays arc taken, blood-samples are taken and the doctor decides to wait and see. It is true that the patient is given more room but the net result is exactly the same. The only positive thing the patient may be left with (but we do not know, for we did not ask it) is the feeling that somebody has been really listening to what she had to say.

\section{DISCUSSION}

What do we learn from all this? First that it appears to be possible to teach general practitioners different habits by means of interview training, habits that have sunk in by the time he has regained his general practice routine. This is the kind of positive result that is certainly not found in every piece of evaluation research. The training especially aimed at unlearning active forms of behaviour and acquiring passive and empathic forms. From the results we can see that the empathy factor has in fact increased for all GPs, whereas the 'directive behaviour' factor, at least for some subjects, has decreased in the post-test figures. The first factor ('informative behaviour') increased for some GPs and decreased for others. It also appears from the post-test figures that more room was given to the patients by the GP to discuss what was bothering them. For practically all GPs the consultations lasted longer and the patients spoke longer both in absolute and relative terms. Also, the GPs were calmer, they looked at their patients more often and in other ways too, they paid 
more attention to and were more interested in their patients.

In short, the doctors have changed by training; not all doctors changed equally much (the GPs 2 and 6 obviously being exceptional), but nevertheless they all changed and, without exception, they changed in the direction aimed for in the training. However, what is striking and in a sense disappointing, is the fact that psychosocial problems were not discussed more of ten (with the exception of one GP). Creating more room for the discussion of psychosocial problems in a consultation does not automatically mean that those problems will be discussed. Of course we must not forget that the training never was intended for teaching therapeutic skills. It has been a training course in listening and in empathy, with the aim of increasing the GPs' (psycho)diagnostic skills. And this, the training did achieve, but no more than that. The conclusions that must be drawn are that those elements of behaviour which are explicitly aimed for in the training, are in fact changeable, but this does not imply that all sorts of other changes of behaviour automatically follow. In fact we did expect this.

For in a situation of psychotherapeutic assistance a Rogerian empathic attitude really appears to stimulate the client to discuss emotional and psychosocial problems. We run up against an interesting phenomenon here: apparently a theoretical concept from social (psychological) scicnces won't work in a medical setting.

A possible explanation for this might be the different role expectations in both situations. In psychotherapeutic situations patients know that they are expected to talk about their problems. This is not always so in a medical setting. Perhaps, patients in the medical setting need time to change their expectations of their doctor and as a consequence need time to change their behaviour in the consulting room. If the doctor continues to act in the more empathic way he/she now acts, patients my learn over many consultations to introduce psychosocial problems, but this will not happen as soon as the doctor gives the first opportunity. And thus the doctor will need to continue to use these new behavioural techniques in order slowly to encourage his patients to divulge these problems to him.

Although the results of the consult hardly seem to have changed, we can speculate about another benefit of the training. It seem acceptable that the patients are more satisfied and more at ease about their illness (not quantified in our experiment) now that they have had the opportunity to discuss their problems completely, whether they are psychosocial or not. As a result of this, the consultation rate per patient per year may decrease. But this is very tentative because ironically the contrary might also appear: when patients are so satisfied with their doctor, they may visit him more often. Further research on this topic will be necessary.

If we cease our speculations here and take a look at the clean results of research, we can finally make the following remarks. If we want doctors to adopt different methods in the therapeutic phase of their consultations, then specific attention must be paid to such methods in training. The results of this study indicate that this conclusion should be regarded as a serious recommendation, since otherwise the 'benefits' would seem negligible in view of the fact that consultations often last twice as long and surgeries run over time, but that the net result is exactly the same.

\section{REFERENCES}

1. Rogers C. R. Client-Centered Therapy. Houghton Mifflin, Boston, 1951; Vrolijk A. Gespreksmodellen, cen geprogrammeerde instructie. Samson, Alphen aan de Rijn, 1971 (only available in Dutch).

2. Byrne P. S. and Long B. E. L. Doctors Talking to Patients. HMSO, London, 1976.

3. Buijs R., Sluijs E. M. and Verhaak P. F. M. Byrne and Long: a classification for rating the interview style of doctors. Soc. Sci. Med. 19, 683-690, 1984.

4. Bensing J. M. and Verhaak P. F. M. Room for the patient. Ned. Tijdschr. Psychol. 37, 19 33. 1982 (available in English).

5. Bensing J. M. and Verhaak P. F. M. Konsultatieprojekt Eindhoven: Gespreksgedrag. NHI, Utrecht. 1980 (only available in Dutch).

6. Bain D. J. G. The relationship between time and clinical management in family practice. J. Fam. Pract. 8, 551-559.

7. Pendleton D. A. and Bochner S. The communication of medical information in general practice consultation as a function of patient's social class. Soc. Sci. Med. 14A, 669-673, 1980. 